\title{
JORNAL DE Políticas EducacionaIS

\section{Progressão continuada no bloco pedagógico: desafios para a gestão escolar em uma escola pública da rede municipal de Santa Maria-RS}

\section{Continuous progression in the pedagogical field: challenges for school management in a public school of the municipal network of Santa Maria-RS}

\section{Progresión continua en el área pedagógica: retos para la gestión escolar en una escuela pública de la red municipal de Santa Maria/RS}

\author{
Katia Rezende Rodrigues ${ }^{1}$ \\ Elisiane Machado Lunardi²
}

Citação: RODRIGUES, K. R.; LUNARDI, E. M. Progressão continuada no bloco pedagógico: desafios para a gestão escolar em uma escola pública da rede municipal de Santa MariaRS. Jornal de Políticas Educacionais. V. 15, n. 12. Março de 2021.

http://10.5380/ipe.v15i0.77581

\section{Resumo}

Este trabalho tem por objetivo apresentar resultados de pesquisa de mestrado profissional em Políticas públicas e Gestão Educacional da UFSM realizada entre os anos de 2016 a 2018, cujo propósito foi analisar as demandas da gestão escolar e os desafios acerca da implementação do regime de progressão continuada no bloco pedagógico do ensino fundamental de uma instituição da rede municipal de Santa Maria-RS. Os processos metodológicos estão embasados na abordagem qualitativa e a metodologia adotada é o estudo

\footnotetext{
${ }^{1}$ Mestre em Políticas Públicas e Gestão Educacional pela Universidade Federal de Santa Maria. Vicediretora de uma escola do município de Santa Maria. Santa Maria, RS. Brasil. Orcid: https://orcid.org/0000-0002-7292-4822. E-mail: bmkrezende@gmail.com ${ }^{2}$ Doutora em Educação pela Faculdade de Educação pela Pontifícia Universidade Católica do Rio Grande do Sul/PUCRS/RS (2012). Atualmente é professora Adjunta da Universidade Federal de Santa Maria no Departamento de Administração Escolar, atuando na graduação com as disciplinas de Pesquisa em Educação, Políticas Públicas, Gestão Educacional e Pesquisa em Educação. É professora credenciada no Programa e Pós-graduação em Políticas Públicas e Gestão Educacional e do Centro de Educação da UFSM. Santa Maria, RS. Brasil. Orcid: https://orcid.org/0000-0002-2276-2466. E-mail: elisiane.lunardi@gmail.com
} 
RODRIGUES, K. R.; LUNARDI, E. M. Progressão continuada no bloco pedagógico: desafios para a gestão escolar em uma escola pública da rede municipal de Santa Maria-RS

de caso. A análise documental teve como base, a legislação de ordem nacional e municipal, bem como documentos oficiais da escola. A construção dos dados ancorou-se nas entrevistas despadronizadas com gestores e professores da escola alvo da pesquisa e na observação participante. Para a análise de dados considerou-se a triangulação dos dados e a análise de conteúdo. Como produto final dessa pesquisa de Mestrado Profissional foi elaborado compartilhadamente o Plano de Gestão Escolar do Bloco Pedagógico no viés do planejamento estratégico. Os estudos apontam que a formação continuada representa a possibilidade de auxiliar na interpretação da progressão continuada no bloco pedagógico. A compreensão da dinâmica da proposta dessa política representa um instrumento de resistência e apoderamento para reivindicar condições adequadas ao funcionamento que promove o sucesso e a permanência dos(as) alunos (as) na escola, para tanto, a gestão escolar pautada na ação participativa e democrática conduz o êxito do ato pedagógico.

Palavras-chave: Políticas Públicas Educacionais, Gestão Escolar, Progressão Continuada, Bloco

Pedagógico.

\begin{abstract}
This study aims to present the results of research of a professional master's degree in Public Policies and Educational Management of UFSM conducted between 2016 and 2018, whose purpose was to analyse the demands of school management and the challenges regarding the implementation of the continuous progression in the pedagogical field of elementary education of an institution of the municipal network of Santa Maria-RS. The methodological processes are based on the qualitative approach and the methodology adopted is the case study. The documentary analysis was based on the national and the municipal legislation as well as the official school documents. The construction of data was anchored in non-standardized interviews with managers and teachers from the target school of this research and participant observation. Data triangulation and content analysis were considered for data analysis. As a final product of this Master's Degree research, the School Management Plan of the Pedagogical Field was elaborated in the strategic planning bias. The studies indicate that continuous education represents the possibility of assisting in the interpretation of the continuous progression in the pedagogical field. The comprehension of the proposal's dynamics of this policy represents an instrument of resistance and empowerment to claim adequate conditions for the functioning, which promotes the success and permanence of the students in the school. Therefore, the school management based on participatory and democratic action leads to the success of the pedagogical act.
\end{abstract}

Keywords: Educational Public Policies, School Management, Continuous Progression, Pedagogical Field.

\title{
Resumen
}

Este trabajo tiene por objetivo presentar los resultados de investigación de maestría profesional en Políticas Públicas y Gestión Educativa de la UFSM realizada entre los años 2016 y 2018, cuyo propósito fue analizar las demandas de la gestión escolar y los desafíos acerca de la implementación del régimen de progresión continuada en el área pedagógica de la enseñanza primaria de una institución de la red municipal de Santa Maria/RS. Los procesos metodológicos se basan en el abordaje cualitativo y la metodología adoptada es el estudio de caso. El análisis documental tuvo como base la legislación de orden nacional y municipal, así como documentos oficiales de la escuela. La construcción de los datos se ancló en las entrevistas no estándar con gestores y profesores de la escuela objeto de la investigación y en la observación participante. Para el análisis de datos se consideró la triangulación de los datos y el análisis de contenido. Como producto final de esta investigación de Maestría Profesional se ha elaborado comparte el Plan de Gestión Escolar del Área Pedagógica en el sesgo de la planificación estratégica. Los estudios apuntan que la formación continuada representa la posibilidad de auxiliar en la interpretación de la progresión continuada en el área pedagógica. La comprensión de la dinámica de la propuesta de esta política representa un instrumento de resistencia y apoderamiento para reivindicar condiciones adecuadas al funcionamiento, lo que promueve el éxito y la permanencia de los alumnos en la escuela. Por lo tanto, la gestión escolar pautada en la acción participativa y democrática conduce el éxito del acto pedagógico.

Palabras clave:Políticas Públicas Educativas, Gestión Escolar, Progresión continua, Área Pedagógica. 
RODRIGUES, K. R.; LUNARDI, E. M. Progressão continuada no bloco pedagógico: desafios para a gestão escolar em uma escola pública da rede municipal de Santa Maria-RS

\section{Introdução}

As reformas educacionais, as políticas públicas e as proposições legislativas vêm aliadas ao reconhecimento e fortalecimento do movimento de democratização da gestão escolar. As mudanças educacionais necessitam ser gestadas no âmbito da escola pública e é nesse sentido que a gestão escolar se constitui como coautor do processo educacional fazendo valer o fim democrático em prol da qualidade da educação.

Nesse sentido, este artigo tem como finalidade apresentar os resultados da pesquisa de Mestrado Profissional que propôs analisar as demandas e os desafios da gestão escolar acerca da implementação do regime de progressão continuada no bloco pedagógico dos anos iniciais do ensino fundamental de uma instituição da rede municipal de Santa Maria-RS.

Como modalidade de Pós-Graduação stricto sensu, o Mestrado Profissional está voltado para a capacitação de profissionais, nas diversas áreas do conhecimento, mediante o estudo de técnicas, processos, ou temáticas que atendam a alguma demanda do mercado de trabalho. Proporciona a aproximação entre universidade e a realidade profissional provocando a articulação entre as discussões teóricas e as situações reais. Essa relação colabora com a aplicabilidade da pesquisa no campo investigado mediante a reflexão da própria práxis. De acordo com o Parecer CNE/CES 0079/2002:

\footnotetext{
"Mestrado Profissional" é a designação do Mestrado que enfatiza estudos e técnicas diretamente voltadas ao desempenho de um alto nível de qualificação profissional. Esta ênfase é a única diferença em relação ao acadêmico. Confere, pois, idênticos grau e prerrogativas, inclusive para o exercício da docência, e, como todo programa de pós-graduação stricto sensu, tem a validade nacional do diploma condicionada ao reconhecimento prévio do curso. (BRASIL, 2002, p. 1).
}

O cotidiano representa o espaço em que emergem temáticas a serem investigadas e consequentemente analisadas em relação às normativas das políticas públicas educacionais que permeiam o contexto escolar. Dessa maneira, as reflexões acerca dos marcos legais da educação vêm ao encontro do crescimento profissional de professores e gestores em relação ao entendimento sobre as políticas públicas que nos são impostas bem como a elaboração de alternativas e ações pertinentes à melhoria da prática educativa.

A temática da progressão continuada no cotidiano escolar requer aprofundamento de estudos sobre políticas públicas educacionais e gestão escolar no seio da escola. Nesse 
RODRIGUES, K. R.; LUNARDI, E. M. Progressão continuada no bloco pedagógico: desafios para a gestão escolar em uma escola pública da rede municipal de Santa Maria-RS

sentido, a abordagem qualitativa permeou o processo de análise interpretativo, pois “[...] a pesquisa qualitativa dirige-se à análise de casos concretos em suas peculiaridades locais e temporais, partindo das expressões e atividades das pessoas em seus contextos locais" (FLICK, 2009, p.37).

Dentro dos propósitos dos mestrados profissionais e sem ferir a organização da escola, a opção metodológica da pesquisa seguiu os princípios do estudo de caso considerando que a investigação foi realizada em uma escola da rede municipal de Santa Maria -RS. 0 estudo de caso permitiu o conhecimento amplo e detalhado do fenômeno investigado dentro de seu contexto de realidade por meio da pesquisa participante (GIL, 2009).

Os estudos sobre a gestão escolar e políticas públicas assumem um papel valioso no delineamento de propostas de gestão de unidades escolares que urgem a melhoria da qualidade da educação. Sendo assim, o tratamento da análise de dados intercorreu-se pela análise de conteúdo (BARDIN, 2009) com vistas ao crescimento profissional em relação ao entendimento sobre as políticas públicas que nos são impostas.

A investigação buscou identificar as fragilidades e forças das ações gestoras no âmbito pedagógico, além de contribuir por meio da elaboração do produto final da pesquisa de Mestrado profissional. A construção compartilhada de um Plano de Gestão Escolar com professores e gestores da escola alvo da pesquisa indicou categorias de análise para acompanhar o percurso do planejamento estratégico a ser executado, monitorado e avaliado pelos profissionais envolvidos.

As categorias elegidas para os procedimentos analíticos finais da dissertação que passamos a apresentar foram: progressão continuada, gestão democrática, bloco pedagógico e planejamento escolar.

\section{Progressão continuada}

Tendo em vista a obrigatoriedade do ensino fundamental para nove anos de duração a partir dos seis anos de idade foi aprovada em 2006, pela lei $\mathrm{n}$ o 11.274 , instaurou-se a Resolução № 007, de 14 de dezembro de 2010, que trata das Diretrizes Curriculares Nacionais para o Ensino Fundamental de nove anos. Este documento admite os três anos iniciais do ensino fundamental como bloco pedagógico, ou seja, corresponde aos alunos de 6, 7 e 8 anos de idades que cursam o $1^{\circ}, 2^{\circ}$ e $3^{\circ}$ ano respectivamente. 
RODRIGUES, K. R.; LUNARDI, E. M. Progressão continuada no bloco pedagógico: desafios para a gestão escolar em uma escola pública da rede municipal de Santa Maria-RS

A mesma resolução, também estabelece que os três anos iniciais do ensino fundamental deve assegurar o processo de alfabetização do aluno sem que se permita a retenção do(a) aluno(a) nesse período. A adoção desta política pública surge como estratégia que tem como objetivo a alfabetização de todos os alunos e alunas até os oito anos de idade e a redução da distorção idade-série nas escolas. 0 artigo 30 da Resolução CNE/CEB № 07/2010 determina que os três primeiros anos devem garantir:

III - a continuidade da aprendizagem, tendo em conta a complexidade do processo de alfabetização e os prejuízos que a repetência pode causar no Ensino Fundamental como um todo e, particularmente, na passagem do primeiro para o segundo ano de escolaridade e deste para o terceiro. (BRASIL,2010, p. 8)

Diante desse panorama, postula-se uma extensão no tempo de alfabetização e uma organização para o fazer pedagógico. 0 chamado regime de progressão continuada significa justamente, um período maior oferecido ao aluno para sua aprendizagem. Sendo assim, o regime de progressão continuada está pautado na concepção de um planejamento sistêmico que garanta continuidade dos conteúdos e a progressão das aprendizagens não vencidas diferindo da promoção automática que se dá quando o aluno, mesmo sem ter assimilado os conteúdos do ano, é promovido.

A progressão continuada, que diferente da promoção automática como ainda pode ser considerada por aí, exige um tratamento com vistas de não vê-la somente como uma oportunidade a mais para o aluno em termos de tempo mas como (re)organização das condutas das ações pedagógicas mesmo sabendo que para as políticas públicas neoliberais, os ciclos e a progressão continuada têm na verdade, outra finalidade. Para elas, a repetência e a evasão geram custos que oneram o Estado indevidamente, não sendo uma preocupação em relação a qualidade da escola propriamente dita (FREITAS, 2003).

Muitas vezes, justifica-se o êxito ou fracasso escolar a partir de explicações tais como a de aptidão ou inaptidão, vocação ou dom. Nesse sentido, a escola desconsidera as desigualdades de âmbito social, econômico ou cultural. Bourdieu (1998) vai além das aparências demonstrando que a aprendizagem não depende somente do professor e do aluno, mas a fatores externo à escola e traduz que:

É provável por um efeito de inércia cultural que continuamos tomando o sistema escolar como um fator de mobilidade social, segundo a ideologia da escola libertadora, quando, ao contrário, tudo tende a mostrar que ele é um dos fatores mais eficazes de conservação social, pois fornece a 
RODRIGUES, K. R.; LUNARDI, E. M. Progressão continuada no bloco pedagógico: desafios para a gestão escolar em uma escola pública da rede municipal de Santa Maria-RS

aparência de legitimidade às desigualdades sociais, e sanciona a herança cultural e o dom social tratado como dom natural (BOURDIEU, 1998, p. 41).

Para essa discussão, Freitas (2003) enfatiza que a função da escola que é ensinar com qualidade todos(as) alunos(as), porém enfatiza a questão do nível socioeconômico e da perspectiva ingênua da equidade educacional sendo que:

"[...] a ideia, neste caso, é reorganizar a escola juntando séries, retirando da avaliação o poder de reter o aluno e introduzindo inovações pedagógicas como forma de compensar os efeitos das diferenças socioeconômicas, em uma tentativa de permitir ritmos diferenciados em espaços maiores de tempo (pelo menos na teoria)" (FREITAS, 2003, p.20).

Dessa maneira, a progressão continuada como política pública tem intenções de colaborar com a equidade educacional e o rompimento do exacerbamento das diferenças socioeconômicas que sobressaem na escola pública. Porém essas questões não são claras quando se inaugura uma política pública educacional no Brasil recolocando o sucesso e a qualidade da educação nas costas dos professores, visto que programas educacionais advindos da política pública de progressão continuada tem seu enfoque no processo de ensino da prática docente.

A partir das respostas dos professores entrevistados, há outras questões que impedem o professor de alcançar seu objetivo maior, que é fazer os alunos evoluírem em seu processo de aprendizagem. Os fatores apontados, giram em torno do tempo do professor e do educador especial com os alunos que apresentam dificuldades de aprendizagem, o número elevado por turma, espaço para reunião pedagógica, infraestrutura da escola para aderir à projetos de apoio e falta de recursos humanos.

Constata-se pelas verbalizações dos(as) entrevistados(as) que o tempo da progressão continuada somente foi pensada em relação ao tempo que é oferecido para esse aluno(a) sem pensar no tempo que o professor necessita para atender o aluno em progressão, e ainda, sem pensar no tempo em que a equipe precisa para esse processo coletivamente através de reuniões ou encontros pedagógicos.

Também foi possível constatar que a maioria dos docentes entrevistados são contrários à progressão continuada apresentando como justificativa, principalmente, as dificuldades em trabalhar com os alunos que não estão alfabetizados até o $3^{0}$ ano ou que não possuem requisitos básicos para avançar. Porém, dos oito entrevistados, três 
RODRIGUES, K. R.; LUNARDI, E. M. Progressão continuada no bloco pedagógico: desafios para a gestão escolar em uma escola pública da rede municipal de Santa Maria-RS

docentes consideram que os alunos do ciclo de alfabetização não deveriam reprovar e são a favor da progressão continuada, até mesmo nas séries seguintes.

O regime de progressão continuada no bloco de alfabetização vem acompanhado, em geral, de proposições relativas a aspectos de organização escolar com os quais se apresenta fortemente articulada com: concepção de educação, concepção de conhecimento, processo de avaliação e teoria de aprendizagem que fundamentam o ciclo, enfim, novas formas de ordenação dos tempos e espaços escolares.

De acordo com os professores, as condições de trabalho existentes são insuficientes para garantir uma aprendizagem efetiva de todos devido: ao grande número de alunos por classe, que dificulta o acompanhamento mais individualizado; à falta de estrutura física, que impede novas parcerias pedagógicas; e de recursos humanos pessoal para esse acompanhamento e à falta de tempo, para reuniões de estudo e planejamento.

Nesta seara, salientamos a importância da formação continuada como espaço de construção de conhecimentos que precisam ser incorporados pela gestão escolar e docentes em função do complexo processo de implementação da política pública de progressão continuada no bloco pedagógico. Os momentos de formação podem representar uma mobilização e um fortalecimento por parte dos professores e ainda, uma melhor compreensão das proposições a partir de sua realidade pedagógica a qual estão inseridas.

\section{Gestão democrática}

Fundamentados nos princípios de autonomia, participação e democracia expressas na Constituição Federal do Brasil, inciso VI do artigo 206, a gestão da escola pública deve ser desenvolvida a partir de uma articulação e uma mobilização dos gestores em prol de uma educação de qualidade (BRASIL, 1988)

Calcados no discurso de gestão democrática, participação e autonomia da escola, as políticas educacionais remetem na contramão um papel central impositor de regulamentos a serem executados pelas instituições escolares. Cabe destacar as contribuições de Dourado (2001) quando salienta que:

A gestão democrática é entendida como um processo de aprendizado e de luta política que não se circunscreve aos limites da prática educativa, mas vislumbra, nas especificidades dessa prática social e de sua relativa autonomia, a possibilidade de criação de canais de efetiva participação e de aprendizado do "jogo" democrático e, consequentemente, do repensar 
RODRIGUES, K. R.; LUNARDI, E. M. Progressão continuada no bloco pedagógico: desafios para a gestão escolar em uma escola pública da rede municipal de Santa Maria-RS

das estruturas de poder autoritário que permeiam as relações sociais e, no seio dessas, as práticas educativas. (DOURAD0, 2001, p. 79, grifo do autor).

0 autor transcende a gestão democrática como estratégia de gestão concreta pautada num processo alicerçado de participação, transparência, liderança e autonomia, sendo que a escola é um espaço capaz de gerar e construir ideias que permitam melhorar tudo aquilo que é próprio dela.

$\mathrm{Na}$ sua essencialidade, as práticas de gestão escolar, correspondem às ações necessárias para a efetivação da prática pedagógica. Essas ações, assim como metas e objetivos pretendidos, pautados em uma gestão democrática e participativa são resultados de decisão coletiva com qualidade. Sendo assim, os gestores apresentam papel fundamental na condução do trabalho coletivo, como mencionado por Paro (1986):

A administração escolar inspirada na cooperação recíproca entre os homens deve ter como meta a constituição, na escola, de um novo trabalhador coletivo que, sem os constrangimentos da gerência capitalista e da parcelarização desumana do trabalho, seja uma decorrência do trabalho cooperativo de todos os envolvidos no processo escolar, guiados por uma "vontade coletiva", em direção ao alcance dos objetivos verdadeiramente educacionais. (PARO, 1986, p.160)

Nesta perspectiva, Lück (2009) colabora quando enfatiza a importância do papel do gestor enquanto líder responsável pela influência intencional e sistemática da escola. 0 gestor, por sua vez, pode levar seus participantes a analisarem seus resultados sob o enfoque dos objetivos educacionais, sob revisão constantemente do desempenho das práticas e de inspiração de valores mais amplos na promoção de ganho para todos.

A política pública de progressão continuada configura uma (re)organização escolar e exigências pedagógicas que requer uma necessária ampliação da autonomia da escola e da democratização de sua gestão, entretanto, há um distanciamento dessas políticas com as reais condições das escolas públicas.

Paro (2014) sinaliza que o poder da educação e do educador existe na medida que se realiza concretamente e que existe um confronto daquilo que a instituição educacional tem intenção de realizar com aquilo que ela efetivamente logra fazer. Nesse sentido, salientamos também que o poder institucional reside na medida que a gestão escolar reconhece a necessidade de (re)avaliar as relações pedagógicas internas para coordenar e efetivar as ações e os objetivos traçados institucionalmente. 
RODRIGUES, K. R.; LUNARDI, E. M. Progressão continuada no bloco pedagógico: desafios para a gestão escolar em uma escola pública da rede municipal de Santa Maria-RS

Salientamos, que esse processo perpassa pela avaliação institucional da escola que conforme Brandalise (2010) representa o produto da integração e entrelaçamento dos processos de avaliação externa e interna. É nessa direção que se torna indispensável a formação continuada do corpo docente no intuito de auxiliar a interpretação das políticas públicas, de superar os ranços da escola tradicional e do processo reprovador.

De acordo com Oliveira (2002), para que as políticas educacionais de correção do fluxo escolar obtenham êxito faz-se necessário primeiramente romper com a crença da não aprendizagem, que conduz a baixa estima e o abandono escolar. E compreender que as reprovações não representam o fracasso dos estudantes, mas o fracasso da escola pública que não está preparada para lidar com as necessidades específicas de aprendizagens desses(as) alunos(as).

Neste viés, a política pública do bloco pedagógico representa um recurso para alfabetizar as crianças com qualidade, reorganizando tempo e espaço para contribuir com um ensino eficiente e também para a correção do fluxo escolar. Porém, não basta criar essas políticas sem movimentar os sujeitos que realmente sustentam o palco principal onde ocorrem essa trama. Nesse sentido, também não basta apenas a boa intenção da gestão que estimula a participação, é necessário potencializar essa gestão e toda a comunidade educacional por meio de uma qualificação e orientação que verdadeiramente a torne participativa.

\section{Bloco pedagógico}

Através da Portaria no. 867, de 4 de julho de 2012, o Ministério da Educação (MEC) amplia o plano de metas estabelecido pelo compromisso: "Todos pela Educação", o qual prevê a alfabetização das crianças até o término do $3^{\circ}$ ano do Ensino Fundamental aos oito anos de idade, estabelecendo esses três anos iniciais do ensino fundamental como bloco pedagógico não passível à retenção escolar, ou seja, garantem a progressão contínua para as crianças matriculadas nessa etapa.

A política pública de progressão continuada do bloco pedagógico pressupõe um acompanhamento permanente do(a) aluno(a) com oferecimento de estratégias que os auxiliem a superar suas dificuldades e avançar junto com seus colegas. Dentro dessa proposta deve-se também, pensar na reestruturação do tempo, do espaço e do currículo escolar, de modo que, todos possam ter oportunidades para aprender. 
RODRIGUES, K. R.; LUNARDI, E. M. Progressão continuada no bloco pedagógico: desafios para a gestão escolar em uma escola pública da rede municipal de Santa Maria-RS

A intenção dessa política ao serem transformadas em práticas se materializam na gestão e no cotidiano escolar. Trata-se, de uma progressão continuada das aprendizagens, que precisa funcionar de maneira equânime para todos na escola e durante todo o processo, não devendo ficar restrita a uma ação isolada.

A mobilização dos espaços e tempos necessários para oportunizar encontros de discussão e sistematização do planejamento pedagógico são ações pertinentes que cumpre à gestão escolar. Aliada à formação continuada de professores e gestores, 0 planejamento escolar passa a ser ferramenta de fundamental importância que “[...] consiste numa atividade de previsão da ação a ser realizada[...]" (LIBÂNEO, p.125, 2004.

Nóvoa (1995) afirma que as reuniões pedagógicas são espaços privilegiados para estudo, reflexão, socialização de experiências, avaliação, planejamento e tomada de decisões. 0 planejamento escolar pode ser entendido como tomadas de decisões antecipadas sobre objetivos desejáveis e passíveis de acontecer. Planejar é criar, é tomar decisões, é determinar, é induzir a cooperação entre pessoas na direção a um alvo desejado (CERVI, 2007).

Entretanto, o planejamento escolar toma fôlego quando a avaliação "[...] assume caráter processual, participativo, formativo, contínuo, cumulativo e diagnóstico e, portanto, visa [re]dimensionar a ação pedagógica" (SANTA MARIA, 2012, p. 5). A avaliação tomada como interface do planejamento integra o processo de gestão escolar. A avaliação pode representar a detecção de necessidades emergentes não previstas e ganha organicidade, flexibilidade, dinamicidade e função de auto-regulação realimentando o próprio planejamento.

Destarte, a avaliação constitui um aspecto fundamental para a efetiva progressão continuada das aprendizagens. A avaliação tem papel preponderante, pois, neste período, a avaliação protagoniza, no mínimo, dois momentos: Primeiro, é fundamental saber o que os alunos já sabem antes de avançar no processo, a chamada "avaliação diagnóstica", e segundo, no decorrer do processo, é necessário também que se tenha claro como os alunos estão avançando, o que chamamos de "avaliação formativa".

Dito isto, acrescenta-se a necessidade da formação continuada em relação às concepções de avaliação aliados ao fortalecimento do planejamento escolar tendo em vista os aportes legais para o bloco pedagógico, pois considera-se que um ensino eficaz não está na reprovação e, consequentemente, na repetição dos conteúdos para aqueles 
RODRIGUES, K. R.; LUNARDI, E. M. Progressão continuada no bloco pedagógico: desafios para a gestão escolar em uma escola pública da rede municipal de Santa Maria-RS

que não conseguiram avançar, mas na obrigação que a escola tem de oferecer oportunidades para que todos aprendam no período mais adequado.

A avaliação assume um papel central para orientar a prática pedagógica e normalizar as ações e encaminhamentos necessários para o efetivo processo de alfabetização. Esteban (2013), salienta que para avaliar é preciso produzir instrumentos e procedimentos que auxiliem a melhor compreensão e interação com os alunos, podendo a avaliação contribuir para outras compreensões do processo pedagógico, demandando uma investigação permanente do processo da aprendizagem e ensino em sua complexidade, sendo preciso uma “[...] redefinição metodológica da avaliação para acompanhar a transformação epistemológica que a emergência de um novo paradigma anuncia" (ESTEBAN, 2013, p. 31).

No que tange os desafios pedagógicos referente aos três anos iniciais do ensino fundamental, é importante destacar a formação continuada como espaço de construção de conhecimentos que precisam ser incorporados pelos docentes em função de complexos processos cognitivos, sócio-afetivos e culturais (GATTI, 2003) incorporados seio do bloco pedagógico. Schön (2000) sugere um triplo movimento no processo de formação de professores, baseado no conhecimento da ação, na reflexão da ação e na reflexão sobre a ação.

\section{Planejamento escolar}

Sabe-se que as políticas públicas educacionais geram impactos diretos no cotidiano da escola que pressupõe uma série de implicações e mudanças relativas às práticas escolares especificamente no que diz à organização e planejamento das ações. Porém, Sarturi salienta que:

[...] não bastam propostas como a progressão continuada, a organização em ciclos, o aumento para nove anos do ensino fundamental, se continuarmos sendo tarefeiros, cumpridores de programas e passivos recebedores de normas. É preciso promover o ciclo dialético: práticateoria-prática para promover as mudanças que serão capazes de transformar os dados estatísticos apresentados pelo Ministério da Educação (SARTURI, 2007, p.7).

No que se refere ao ciclo de alfabetização, a organização curricular deve ser pensada de modo que as aprendizagens sejam garantidas. Para dar conta das demandas frente à progressão continuada dos três anos iniciais no bloco pedagógico, cabe as redes 
RODRIGUES, K. R.; LUNARDI, E. M. Progressão continuada no bloco pedagógico: desafios para a gestão escolar em uma escola pública da rede municipal de Santa Maria-RS

de ensino pensar e planejar a própria organização do espaço escolar tendo em vista características específicas de cada instituição.

Vale salientar, a importância do planejamento em diferentes esferas, pois as discussões dos processos de atendimento acerca do bloco pedagógico do ensino fundamental envolvem o desafio de repensar as organizações da rotina escolar e das demandas em relação ao regime de progressão continuada. 0 planejamento se torna essencial para balizar o processo de alfabetização inicial bem como para oferecer suportes aos anos seguintes de escolarização.

Nesta perspectiva, o plano estratégico consiste em um instrumento de trabalho dinâmico que elenca os principais problemas e objetivos dentro da meta a ser alcançada. Com a gestão estratégica abrem-se possibilidades para a expressão do poder dos actores escolares, concebidos agora como agentes dotados de intencionalidade e capacidade de acção (SILVA, 1999).

O planejamento estratégico representa uma forma de estabelecer e manter um sentido de direcionamento do trabalho pedagógico, um processo pelo qual a organização é mantida em seu curso, fazendo ajustes à medida que o contexto muda, sendo repensado e reorganizado a partir de reflexões sobre a práxis. Usar estratégia é realizar as atividades necessárias para chegarmos ao objetivo desejado e, para que isso aconteça, é preciso o envolvimento de todos, implementando esforços para sua realização (ESTEVÃO, 2006).

Tendo em vista a elaboração do produto final, a construção do Plano de Gestão Escolar do Bloco Pedagógico da escola alvo de pesquisa foi elaborado em consonância com triangulação de dados e análise de conteúdo do Curso de Mestrado Profissional em Políticas Públicas e Gestão Educacional a partir da participação coletiva com os professores(as) viabilizando um processo de formação continuada pertinente a prática docente.

Os professores alfabetizadores se envolveram na construção e previsão de ações a serem realizadas visando alcançar determinados objetivos, e envolvidos também na obtenção de melhores resultados do processo educativo. Para Lück (2000), o uso do planejamento estratégico na gestão escolar é fundamental para guiar a organização da escola, produzindo decisões fundamentais e fortalecendo a visão da instituição. Nesse sentido, o plano de gestão escolar prevê uma organização escolar, para que não apenas acompanhe a dinâmica social, mas se antecipe a ela, como condição para que se ofereça aos alunos um processo educacional significativo. 
RODRIGUES, K. R.; LUNARDI, E. M. Progressão continuada no bloco pedagógico: desafios para a gestão escolar em uma escola pública da rede municipal de Santa Maria-RS

Para tanto, o Plano de Gestão Escolar do Bloco Pedagógico representou uma ferramenta essencial para balizar o trabalho da gestão escolar contribuindo de maneira significativa para a (re)organização e planejamento escolar. Vimos a necessidade de agregar o planejamento estratégico com a formação continuada da equipe docente pois, aliar teoria e prática, discussões sobre concepções de ensino e de avaliação implicam uma melhoria significativa e necessária a qualidade do ensino e a formação do corpo docente.

\section{Palavras conclusivas}

Analisar as demandas e os desafios da gestão escolar acerca da implementação do regime de progressão continuada no bloco pedagógico nos anos iniciais do ensino fundamental de uma instituição da rede municipal de Santa Maria/RS constituiu o foco central do estudo do Curso de Mestrado Profissional em Políticas Públicas e Gestão Educacional da UFSM.

Os estudos sobre a gestão escolar e políticas públicas assumem um papel valioso no delineamento de propostas de gestão de unidades escolares que urgem a melhoria da qualidade da educação.

Em consonância com os relatos e as entrevistas, professores(as) e gestores(as) sinalizaram que a progressão continuada foi pensada somente em relação ao tempo que é oferecido para o aluno sem pensar no tempo que o professor necessita para atender o aluno em progressão e que as dificuldades de o aluno progredir envolvem outras questões como: maturidade, realidade socioeconômica, comprometimento familiar, problemas psicológicos ou de ordem neurológica.

Contudo, professores e gestores enfatizaram que as condições de trabalho existentes são insuficientes para garantir uma aprendizagem efetiva de todos devido: ao grande número de alunos por classe, que dificulta o acompanhamento mais individualizado; à falta de estrutura física, que impede novas parcerias pedagógicas; e de recursos humanos para esse acompanhamento e à falta de tempo, para reuniões de estudo e planejamento.

A partir dos depoimentos entende-se que os desafios da gestão escolar, giram em torno principalmente da dificuldade de tempo de planejamento coletivo, falta de sistematização e organização do trabalho pedagógico além da precariedade da estrutura física. 
No que se refere especificamente ao bloco pedagógico, em seus discursos, os docentes acordam que toda criança apresenta um ritmo de desempenho influenciados por sua história de vida, cultural, social, familiar, biologia e psicológica, porém, consideram um desafio adequar esse ritmo ao que se espera em termos de exigências de um sistema avaliador. As queixas maiores entre os docentes foram: as turmas heterogêneas e numerosas, níveis de aprendizagem diversificados, participação da família e inclusão.

Neste estudo observou-se fragilidades em torno da política pública da progressão continuada no bloco pedagógico, entretanto, a formação continuada representa a possibilidade de superar os desacertos que professores e gestores apresentam sobre algumas concepções sobre a alfabetização e a progressão continuada e também sobre a inclusão, que tem sido colocada como obstáculo para a melhoria do ensino. É urgente, então, uma nova e verdadeira consciência sobre a aprendizagem e principalmente sobre um novo paradigma de avaliação e formação continuada.

Dessa forma, o complexo processo de ensino e aprendizagem compreende um comprometimento com a organização do trabalho pedagógico de maneira compartilhada com professores e gestores, sem presumir a "promoção automática", mas configurando uma postura que garanta a progressão continuada como política educacional comprometida com a melhoria do ensino, principalmente por questão de justiça, das camadas populares.

Portanto, diante das constatações desse estudo e de reflexões em torno do eixo central da pesquisa realizada para a Dissertação de Mestrado Profissional, salienta-se a relevância o papel da gestão escolar para o sucesso da implementação das políticas públicas educacionais. Certamente uma postura comprometida com o ensino de qualidade e pautada na ação participativa e democrática conduz para o êxito do ato pedagógico, razão de ser da escola.

\section{Referências}

BARDIN, L. Análise de Conteúdo. Lisboa, Portugal; Edições 70, LDA, 2009.

BOURDIEU, Pierre. Escritos de Educação. Petrópolis: Vozes, 1998.

BRANDALISE, Mary Ângela T. Avaliação institucional da escola: conceitos, contextos e práticas. Olhar de professor. Ponta Grossa, 13(2): 315-330, 2010. Disponível em: 
RODRIGUES, K. R.; LUNARDI, E. M. Progressão continuada no bloco pedagógico: desafios para a gestão escolar em uma escola pública da rede municipal de Santa Maria-RS

<http://www.revistas2.uepg.br/index.php/olhardeprofessor/article/viewFile/3220/23 60>. Acesso em jul 2016 a jul 2018.

BRASIL. Constituição Federal de 1988. Promulgada em 5 de outubro de 1988. Disponível em: <http://www.planalto.gov.br/ccivil 03/constituicao/constituição.htm>. Acesso em: 5 ago. 2017.

BRASIL. Ministério da Educação. Conselho Nacional da Educação. Câmara da Educação Básica. Parecer no 79/2002 de 12.03.2002. Disponível em: <http://portal.mec.gov.br/cne/arquivos/pdf/2002/pces079 02.pdf >. Acesso em: 07 Jun. 2017.

BRASIL. Lei $\mathbf{n}^{\circ}$ 11.274/06, de 06 de fevereiro de 2006. Altera a redação dos artigos. 29, 30, 32 e 87 da Lei no 9.394, de 20 de dezembro de 1996, que estabelece as diretrizes e bases da educação nacional, dispondo sobre a duração de 9 (nove) anos para o ensino fundamental, com matrícula obrigatória a partir dos 6 (seis) anos de idade. 2006.

BRASIL Ministério da Educação. Conselho Nacional de Educação. Câmara de Educação Básica. Resolução № 4, de 13 de julho de 2010 - Define Diretrizes Curriculares Nacionais Gerais para a Educação Básica. Diário Oficial. Brasília: MEC, CNE, CEB, 2010.

BRASIL. Ministério da Educação, Conselho Nacional de Educação. Diretrizes curriculares para o Ensino Fundamental de nove anos. Resolução CNE no 7, de 14 de dezembro de 2010.

CERVI, Rejane de Medeiros. Planejamento e Avaliação Educacional. Curitiba, Ibpex, 2007.

DOURAD0, Luiz Fernando. A reforma do estado e as políticas de formação de professores nos anos de 1990. In: DOURADO, Luiz Fernando; PARO, Vitor Henrique (orgs). Políticas públicas e educação básica. São Paulo: Xamã, 2001.

ESTEBAN, Maria Teresa. Ser professora: avaliar e ser avaliada. In.: ESTEBAN, Mara Teresa (Org.). Escola, Currículo e avaliação. 4. ed. São Paulo: Cortez, 2013.

ESTEVÃO, Carlos. Cadernos de Organização e Gestão Curricular. Editora Instituto de Inovação Educacional. $\quad$ Lisboa, 2002.2 Disponível em:<http://www.crmariocovas.sp.gov.br>. Acesso em: 15 set. 2017.

FLICK, U. Introdução à Pesquisa Qualitativa. 3ํㅡㄹ ed. Porto Alegre. Artmed, 2009.

FREITAS, Luiz Carlos de. Ciclos, seriação e avaliação: confrontos de lógicas. São Paulo. Moderna, 2003.

FREITAS, Luiz Carlos de. Os reformadores empresariais da educação: da desmoralização do magistério à destruição do sistema público de educação. Educ. Soc., Campinas, v. 33, n. 119, p. 379-404, abr.-jun. 2012. 
GATTI, Bernadete A. Formação continuada de professores: a questão psicossocial. In: Cadernos de Pesquisa, 2003, n.119, p.191-204. Disponível em: $<$ http://www.scielo.br/scielo.php?pid=S0100-

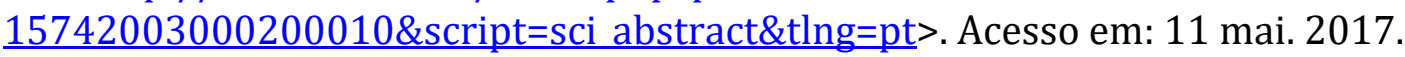

GIL, A. C. Métodos e Técnicas de Pesquisa Social. 6. ed. São Paulo: Atlas, 2009.

LIBÂNEO, J.C. Organização e Gestão da Escola: Teoria e Prática, 5. ed. Goiânia, Alternativa, 2004.

LÜCK, H. A aplicação do planejamento estratégico na escola. Gestão em Rede, Brasília, n. $19, \quad$ p. 8-13, 2000.<http://www.crmariocovas.sp.gov.br/pdf/luck planejamento.pdf >. Acesso no período Ago. 2017 a jul 2018.

LÜCK, H. Gestão Participativa na Escola. Ed. 5. Petrópolis/RJ: Vozes, 2009.

NÓVOA, Antônio (org.). Os professores e a sua formação. 2 ed. Lisboa, Publicações Dom Quixote, 1995.

OLIVEIRA, João Batista Araujo e. Correção do fluxo escolar: um balanço do programa Acelera Brasil (1997-2000). Cadernos de Pesquisa, n. 116, p. 117-215, jul. 2002. Disponível em: <http://www.scielo.br/pdf/cp/n116/14403.pdf>. Acesso em: 23 abr. 2018.

PARO, V. H. Administração escolar: introdução crítica. 3.ed. São Paulo: Cortez, 1986.

PARO, V.H. Educação como exercício do poder: crítica ao senso comum em educação. 2. ed. São Paulo: Cortez, 2014.

PARO, V. H. Reprovação escolar: renúncia à educação. 2.ed. São Paulo: Xamã, 2003.

SANTA MARIA. Resolução CMESM № 32, de 18 de junho de 2012 definiu Diretrizes Curriculares para o Ensino Fundamental no Sistema Municipal de Ensino de Santa Maria - RS, 2012.

SARTURI, Roseane Carneiro. Ensino fundamental para nove anos: espaços de legitimação no cotidiano escolar. Disponível em: <http://www.pucpr.br/eventos/educere/educere2009/anais/pdf/3651 2027.pdf>.

Acesso em: 15 ago. 2017.

SCHÖN, D.A. Educando o Profissional Reflexivo: um novo design para o ensino e a aprendizagem. Trad.Roberto Cataldo Costa. Porto Alegre: Artmed, 2000, 256p.

SILVA, Eugénio Alves da. Gestão estratégica e projecto educativo. Escola e Projecto: actas do Seminário, p. 63-103, 1999.

VEIGA, Ilma Passos A. Professor: tecnólogo de ensino ou agente social. In: AMARAL \& VEIGA (Coord.). Formação de professores: políticas e debates. Campinas, SP: Vozes, 2002. 
RODRIGUES, K. R.; LUNARDI, E. M. Progressão continuada no bloco pedagógico: desafios para a gestão escolar em uma escola pública da rede municipal de Santa Maria-RS

Recebido em Novembro de 2020

Aprovado em Janeiro de 2021

Publicado em Março de 2021 

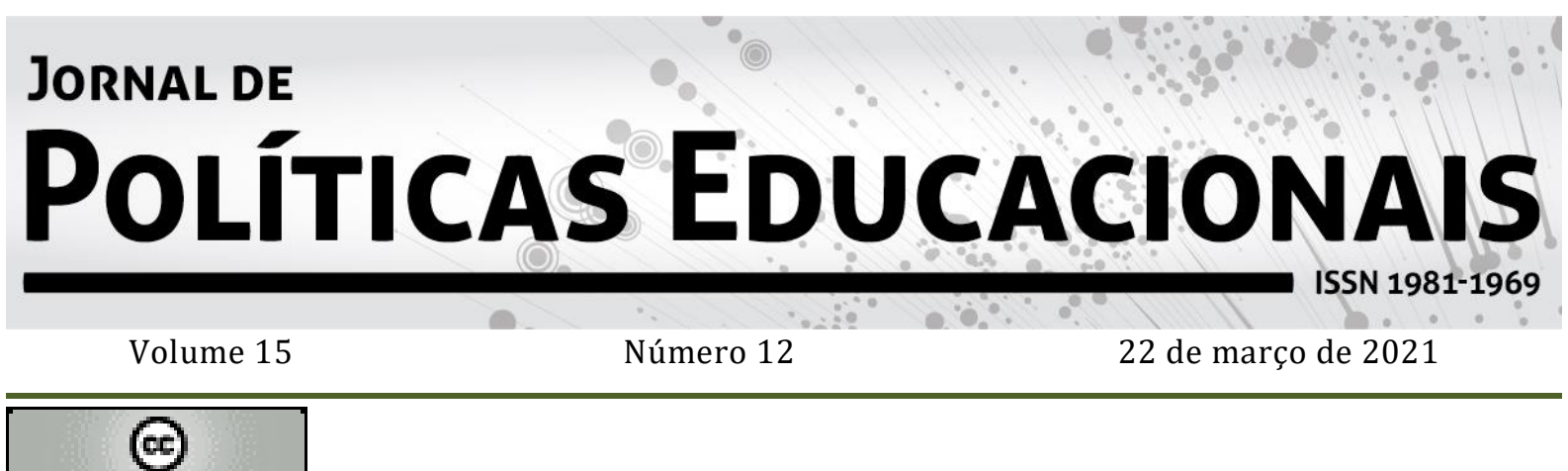

SORERIGHISRESERVED O Copyright é retido pelo/a autor/a (ou primeiro co-autor) que outorga o direito da primeira publicação ao Jornal de Políticas Educacionais. Mais informação da licença de Creative Commons encontram-se em http://creativecommons.org/licenses/by-nc-nd/2.5. Qualquer outro uso deve ser aprovado em conjunto pelo/s autor/es e pelo periódico.

JoRnAl De Políticas EduCACIONAIS é uma publicação do Núcleo de Políticas Educacionais do Setor de Educação da Universidade Federal do Paraná - NuPE/UFPR, em consórcio com a Linha de Pesquisa em Políticas Educacionais do Programa de Pós-Graduação em Educação - PPGE/UFPR, que aceita colaboração, reservando-se o direito de publicar ou não o material espontaneamente enviado à redação. As colaborações devem ser enviadas ao NuPE/UFPR, conforme orientações contidas nas páginas do periódico na internet: http://revistas.ufpr.br/jpe.

INDEXAÇÃO:

BASE DE DADOS
Sumário.Org
Google Scholar
BASE
Dimensions

DIRETÓRIOS
Erih Plus
Latindex
Diadorim
EZB
ROAD
Journal 4-free

\author{
ÍNDICES \\ Index Copernicus \\ Cite Factor \\ PORTAIS \\ LiVre \\ Capes \\ Science Open \\ World Wide Science
}

(Periódico integralmente disponível apenas em via eletrônica)

Jornal de Políticas Educacionais / Núcleo de Políticas Educacionais da Universidade Federal do Paraná NuPE/UFPR - v.1, n. 1 (1o semestre de 2007) - Curitiba: NuPE/UFPR.

Volume 15, número 12 - Março de 2021

ISSN 1981-1969

1. Educação - Periódicos. 2. Política Educacional - Periódicos. I. NuPE/UFPR 
RODRIGUES, K. R.; LUNARDI, E. M. Progressão continuada no bloco pedagógico: desafios para a gestão escolar em uma escola pública da rede municipal de Santa Maria-RS

Comitê Editorial:

Elisângela Scaff (UFPR)

Daniela de Oliveira Pires (UFPR)

Conselho Editorial:

Andréa Barbosa Gouveia (UFPR - Brasil), Angela Maria Martins (FCC, Brasil), Antonia Almeida Silva (UEFS, Brasil), Cesar Tello (Universidad Nacional Tres Febrero, Argentina), Cristiane Machado (Unicamp- Brasil), Elton Luiz Nardi (UNOESC, Brasil), Fernanda Saforcada (Universidad de Buenos Aires - UBA - Argentina), Gladys Beatriz Barreyro (USP - Brasil), Gilda Cardoso Araújo (UFES - Brasil), Gustavo Enrique Fischman (Arizona State University - USA), Janete Maria Lins de Azevedo (UFPE, Brasil), Jefferson Mainardes (UEPG Brasil), João Ferreira de Oliveira (UFG - Brasil), Jorge Manuel Gorostiaga (UNSAM - Argentina), Juca Gil (UFRGS - Brasil), Luciana Rosa Marques (UFPE, Brasil), Luiz Souza Júnior (UFPB - Brasil), Marcia Aparecida Jacomini (Unifesp-Brasil), Maria Dilnéia Espíndola Fernandes (UFMS, Brasil), Ney Cristina Monteiro de Oliveira (UFPA - Brasil), Nicolás Bentancur, (Universidad de la República de Uruguay), Nora Krawczyk (Unicamp- Brasil) Rodrigo da Silva Pereira (UFBA, Brasil), Robert Verhine (UFBA - Brasil), Rosana Cruz (UFPI - Brasil), Rubens Barbosa Camargo (USP - Brasil), Sebastián Donoso Díaz (Universidad de Talca Chile), Theresa Adrião (UNICAMP - Brasil), Vera Maria Vidal Peroni (UFRGS - Brasil).

Créditos e Agradecimentos:

Revisão de Língua Portuguesa, Abstract e Resumen: Programa de apoio às publicações científicas periódicas da UFPR

Arte e diagramação: Tiago Tavares (tiagotav@gmail.com)

Jornal de Políticas Educacionais

Universidade Federal do Paraná

Setor de Educação

Núcleo de Políticas Educacionais - NuPE/UFPR

Avenida Sete de Setembro, 2645

2 o andar, Sala 213

80.230-010 - Curitiba - PR - Brasil

Tel.: 41-3535-6264

jpe@ufpr.br

http://revistas.ufpr.br/jpe 